\title{
Challenges of C1-Inhibitor Concentrate Self-Administration
}

\author{
H.B. Boysen ${ }^{a} \quad$ L. Bouillet ${ }^{b} \quad$ E. Aygören-Pürsün ${ }^{c}$ \\ ${ }^{a}$ Executive Director of HAEi, Aarhus, Denmark; ${ }^{b}$ National Reference Center of Angioedema, Grenoble University \\ Hospital, Grenoble, France; ' Johann Wolfgang Goethe-University Hospital, Frankfurt, Germany
}

\author{
Key Words \\ Hereditary angioedema · Self-administration - Barriers . \\ Challenges · Quality of life
}

\begin{abstract}
Self-administration of therapy can help hereditary angioedema (HAE) patients regain control of their disease or reduce its impact and improve the quality of their lives. However, data from a self-administration survey, and subsequent discussion at an international HAE expert meeting, identified several barriers to self-administration therapy. These barriers include difficulty in administration technique, availability of nursing resources and the mental capacity of the patient. Encouragingly, international HAE experts identified that once a patient has acquired self-administration skills, they generally retain them in the long-term. As patient uptake increases, it was recommended that follow-up management plans should be established to address any issues from the patient's perspective.

Copyright $\odot 2013$ S. Karger AG, Basel
\end{abstract}

\section{Introduction}

Awareness of hereditary angioedema (HAE) is extremely low and diagnosis of the condition may take several years with a mean delay to diagnosis of as much as 16 years [1]. This emphasises the urgent need to raise aware-

\section{KARGER}

E-Mail karger@karger.com

www.karger.com/iaa ness of the disease among clinicians and within families who carry a hereditary predisposition to the condition. Surprisingly, family screening is not always performed despite HAE being an autosomal dominant disease with $50 \%$ penetrance [2].

The mechanisms underlying an HAE attack remain relatively unknown and the severity of symptoms is highly variable both within and between patients. Episodes of swelling can occur in the extremities, face, trunk, airways or abdominal areas (fig. 1). The uncertainty of timing, severity and length of an HAE attack can cause great anxiety for patients given that the swelling can be fatal if it occurs in the larynx; the risk of dying from an airway obstruction, if left untreated, has been estimated to approach $40 \%$ [3].

Currently, the management of HAE focuses on providing rapid relief or prevention of symptoms during an attack. Treatment options approved in Europe for acute attacks include plasma-derived C1 esterase inhibitor (C1INH) concentrate (Berinert, Cetor and Cinryze), recombinant C1-INH (Rhucin, Ruconest) and bradykinin $\beta_{2}$ receptor antagonist [icatibant (Firazyr)]. Long-term prophylaxis is approved with C1-INH concentrate (Cinryze) and also traditionally involves antifibrinolytics or androgens (e.g. danazol or stanozolol), although approval varies across Europe. Until recently, patients had to visit the clinic, emergency department or hospital for treatment. The option of self-administration is now being offered to patients as it is thought that this therapy option can help 

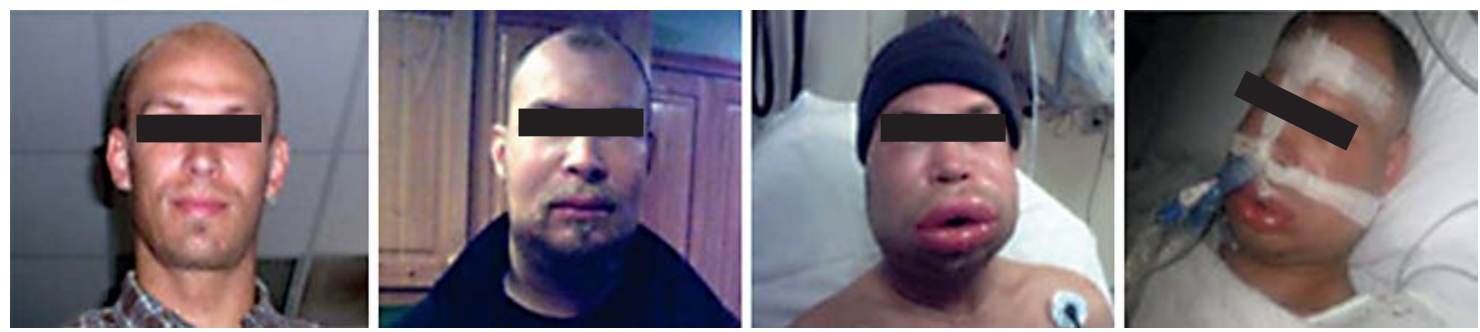

Fig. 1. Progression of an HAE attack (image source, Bygum et al. [1]).

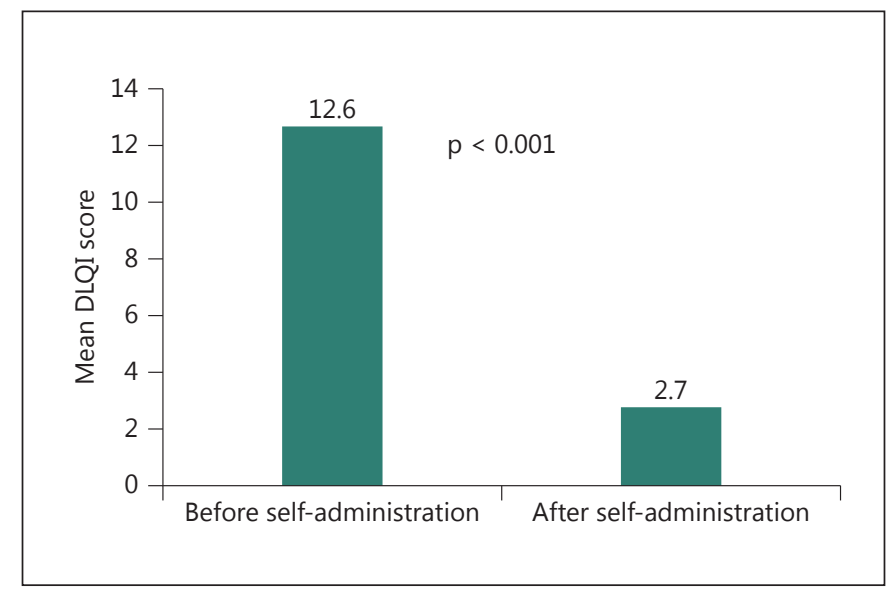

Fig. 2. Mean DLQI score of 7 patients before and after self-administration HAE therapy [6]. DLQI = Dermatology life quality index.

patients regain control/reduce the impact of disease and improve the quality of their lives [4].

Several studies have explored the impact of HAE on health-related quality of life. Some investigations used the short form 36 (SF-36) and also the dermatology life quality index (DLQI), which are useful for comparing HAE to other diseases $[5,6]$. Investigations show that self-administration of treatment was associated with improvements in the mean DLQI score ( $\mathrm{p}<0.001$; fig. 2$)$ and in both physical $(p=0.0001)$ and psychological parameters $(p=0.0033)$ on the SF-36 [6]. More recently, disease-specific questionnaires have been developed $[7,8]$ which aim to specifically assess health-related quality of life in HAE patients.

\section{Methods}

To assess the current practice of HAE self-administration treatment across Europe, Canada and the USA, a survey was sent to a group of experts in the field of HAE (including physicians, nurses and a patient-expert) prior to attendance at an international HAE expert meeting organised for the purpose of seeking advice on current practice in self-administration treatment of HAE. For further details of the survey refer to the paper by Caballero et al. [9] in this supplement ('Current status of implementation of self-administration training programmes in various regions of Europe, Canada and the USA in the management of hereditary angioedema'). At the international HAE expert meeting the results of the questionnaire were used to direct discussion. In particular, participants considered some of the challenges that physicians, nurses and patients face and how they may be overcome.

\section{Challenges and Solutions}

International HAE expert meeting participants believed all HAE patients should be considered for self-administration if the patient is willing; however, some patients may need more support than others and some may not be eligible for self-administration. The main challenge identified for self-administration patients was obtaining the necessary skill set (fig. 3). Discussion identified that once a patient has acquired the skills for administration, for both intravenous and subcutaneous infusion, they generally retain them as a long-term competency. The time between attacks is not a reason to not offer a patient the option to self-administer.

The current guidelines for treatment indicate that all patients should participate in a training programme over several sessions to ensure that patients and, if applicable, a training partner, have had sufficient practice to be familiar and confident with the technical and medical aspects of self-administration [10]. The clinical experts revealed that patients were learning the necessary skill set faster than expected and that it was common practice that patients attended a training session for $2 \mathrm{~h}$ followed by a follow-up session, as described elsewhere in this supplement (see Symons et al. [11] 'Practical approach to self-administration of intravenous C1-INH 
Fig. 3. What are the main hurdles to enable/train patients to self-administer Berinert?

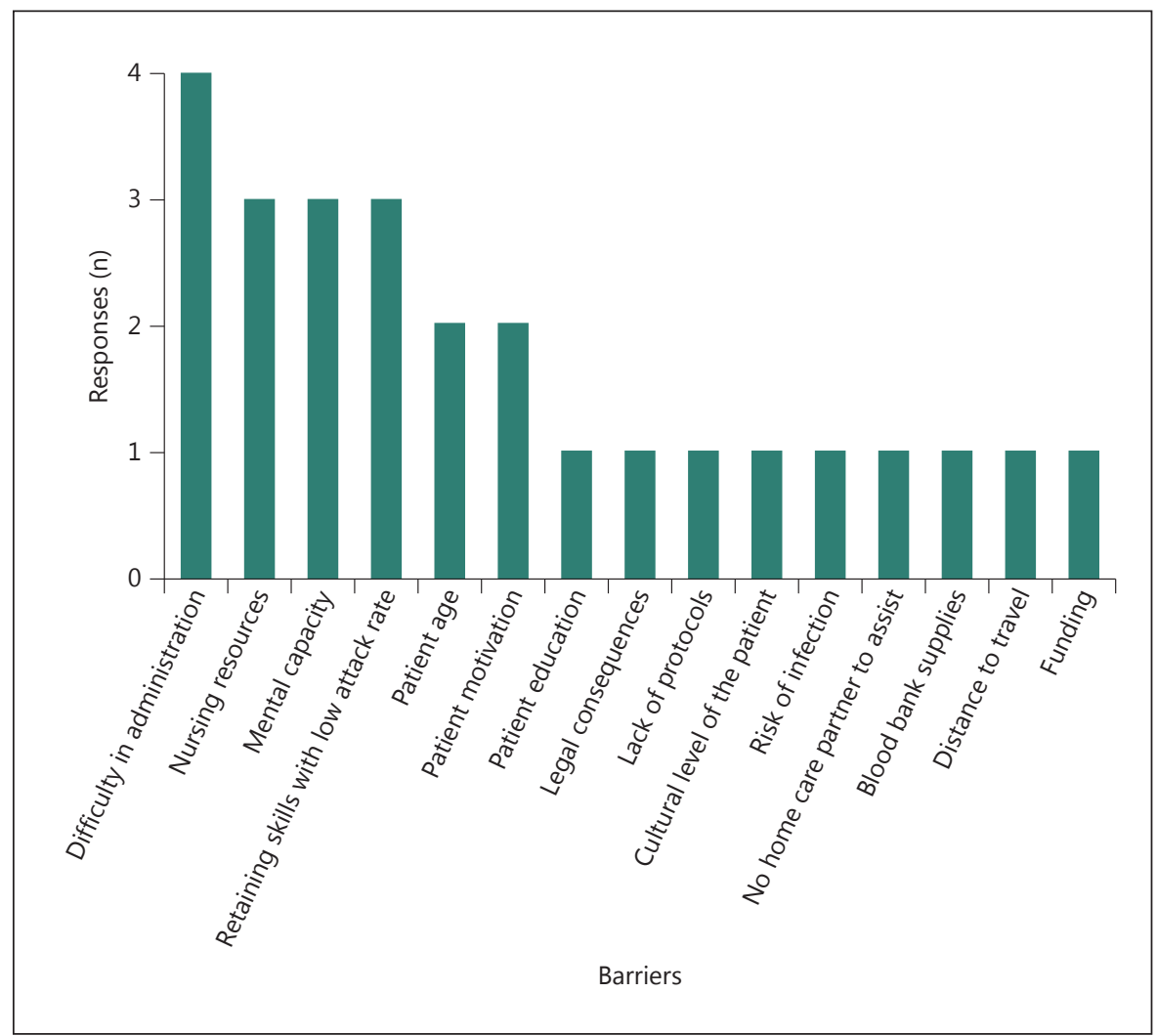

concentrate: a nursing perspective' for details of training schedules).

For self-administration, patients are responsible for self-diagnosis of an attack and, although rare, there is the risk of misinterpretation. Patients are thought to be aware of the onset of an attack, allowing ample time to administer therapy and minimise the severity and length of an attack. Clinical experts at the international HAE expert meeting recommended reporting all attacks and any unusual or lingering symptoms to ensure there are no untreated symptoms. Monitoring of attacks may also help assess a patient's ability to manage their disease state. The decreased contact between patient and physician is addressed by having agreed follow-up visits to assess progress and to review the patient reports. International HAE expert meeting participants discussed the timing between patient visits; initially once every 3 months was recommended to ensure correct management of their condition, followed by once every 6 months when the patient was more comfortable with selfadministration. For the benefit of patient and physician, it was agreed that an acute action plan should be arranged to permit the patient to take appropriate action if self-administration is ineffective.

Challenges of C1-Inhibitor Concentrate Self-Administration
Due to the rarity and potential severity of the disease, more needs to be done to raise awareness of the condition amongst physicians. At the international HAE expert meeting, it was remarked that some patients reported not attending hospital during an attack because the time to treatment could be delayed by a lack of HAE experience of the treating physician in the emergency department. It was reported that many physicians do not understand the disease and they would often administer therapy directed at histamine-induced angioedema instead of the appropriate therapy. Indeed, some physicians do not understand the urgency for treatment if the attack is not likely to be fatal. In discussion, the need for acute action treatment plans for the patient and the treating physician were stressed. In raising awareness of the condition, patients may get the rapid response they need, which could potentially be life-saving.

Increasing awareness of HAE may also lead to better facilities being provided for patients who have to learn how to self-administer treatment. Advice from the participants was that there are only a minority of places with good facilities. This makes self-infusion a challenge for new patients to learn. In addition, because not all attacks occur in the home, it is often difficult to self-administer 
Table 1. Guidance on HAE self-administration therapy

\begin{tabular}{ll}
\hline Key information & Reasons for usefulness \\
\hline $\begin{array}{l}\text { Administer treatment } \\
\text { prior to an attack }\end{array}$ & $\begin{array}{l}\text { This will help to prevent an attack } \\
\text { or lead to rapid recovery and } \\
\text { minimal attack duration. }\end{array}$ \\
\hline $\begin{array}{l}\text { Administer treatment } \\
\text { early and when hydrated }\end{array}$ & $\begin{array}{l}\text { This will aid infusion to ensure full } \\
\text { treatment is achieved rapidly. }\end{array}$ \\
\hline Avoid central lines & $\begin{array}{l}\text { Infection rates are generally very } \\
\text { low but increase with the use of } \\
\text { central lines; avoid them to } \\
\text { minimise infection rates. }\end{array}$ \\
\hline
\end{tabular}

HAE $=$ Hereditary angioedema

Table 2. Advantages and disadvantages of prescribing self-administration HAE therapy

\begin{tabular}{ll}
\hline Advantages & Disadvantages \\
\hline $\begin{array}{l}\text { Able to treat an attack rapidly } \\
\text { which minimises days off work } \\
\text { or school }\end{array}$ & $\begin{array}{l}\text { Decreased patient/physician } \\
\text { contact }\end{array}$ \\
\hline Able to manage own disease & Fear of self-infusion \\
\hline Able to travel & Training session required \\
\hline Improved patient quality of life & $\begin{array}{l}\text { May find it difficult to } \\
\text { obtain venous access }\end{array}$ \\
\hline
\end{tabular}

Subcutaneous infusion is more

discreet than intravenous

infusion

$\mathrm{HAE}=$ Hereditary angioedema.

medication with some patients choosing not to infuse as they do not want to be seen injecting in public.

The final barrier discussed at the international $\mathrm{HAE}$ expert meeting was the legal ramifications of offering selfinfusion to patients in some European countries. For example, in Germany, the prescribing physician is responsible for the patient regardless of the location of treatment and therefore not all physicians will encourage self-administration. More needs to be done to demonstrate that self-administration is a viable option and that self-diagnosis and self-administration may be beneficial to the patient by reducing the time to treatment, decreasing attack severity and improving time to recovery. The conve- nience of self-administration and the independence that stems from this also improves patients' quality of life. In accordance with the current guidelines, all voluntary patients should be considered for self-administration and, after discussion, a decision should be made if the patient is willing and able to self-administer therapy [10]. Discussion of treatment management with patients during regular check-ups should allow patients and physicians to come to a mutual agreement that suits both parties.

\section{Factors to Help Those Newly Diagnosed with HAE}

Treatment of an HAE attack can be a daunting process. Discussion at the international HAE expert meeting highlighted a number of key points to aid self-administration, as shown in table 1.

Self-administration enables patients to have control of their disease management. Patients feel in control of their lives with self-treatment enabling them to lead a normal life, being able to work and travel and minimising days off from work or school.

As with all treatments there are advantages and disadvantages; however, the advantages outweigh the disadvantages (table 2). The options for self-administration treatment include intravenous and subcutaneous infusion which enables patients to select the most appropriate one for their needs. Many patients find the independence and improved quality of life gained with self-infusion empowers them to manage the disease instead of being managed by it.

\section{Conclusion}

Raising the awareness of HAE amongst healthcare providers globally may help increase diagnosis and treatment of HAE. With the increase in treatment options and approvals for self-administration, physicians are beginning to offer self-administration as a viable treatment option that should be considered for all HAE patients. As patient uptake increases, a follow-up management plan should be established to address any issues from the patient's perspective and to identify key areas for follow-up. Having the choice of when and where to self-administer provides the flexibility needed for successful treatment. Experience with self-administration to date suggests that patients should have the confidence that most challenges they encounter can be resolved by their educated local nurse or treating physician. 


\section{Disclosure Statement}

Mr. Boysen is the Executive Director of HAEi - International Patient Organization for C1 Inhibitor Deficiencies, which has received or receives unrestricted educational funding from CMIC Holdings Co., CSL Behring, Dyax Corp., Santarus Inc., Shire, Sigma-Tau Group, Sobi - Swedish Orphan Biovitrum and ViroPharma Incorporated.
Dr. Bouillet has received honorarium from CSL Behring, Shire and ViroPharma for attending advisory boards and conferences.

Dr. Aygören-Pürsün has been involved in consultancy work and advisory boards for CSL Behring, Shire, ViroPharma and Sobi and has received grants and given lectures/spoken at symposia for CSL Behring, Shire and ViroPharma.

\section{References}

1 Bygum A, Aygören-Pürsün E, Caballero T, Beusterien K, Gholizadeh S, Musingarimi P, Wait S, Boysen $\mathrm{H}$ : The hereditary angioedema burden of illness study in Europe (HAEBOIS-Europe): background and methodology. BMC Dermatol 2012;12:4.

$\checkmark 2$ Lunn ML, Santos CB, Craig TJ: Is there a need for clinical guidelines in the United States for the diagnosis of hereditary angioedema and the screening of family members of affected patients? Ann Allergy Asthma Immunol 2010;104:211-214.

3 Bork K, Siedlecki K, Bosch S, Schopf RE, Kreuz W: Asphyxiation by laryngeal edema in patients with hereditary angioedema. Mayo Clin Proc 2000;75:349-354.

4 HAEi International Patient Organization for C1 Inhibitor Deficiencies: State of management of HAE in Europe. 2011. http://www. haeday.org/sites/default/files/upload/ English\%20PDF-\%20HAEi_Report.pdf (accessed 24 September 2012).
Lumry WR, Castaldo AJ, Vernon MK, Blaustein MB, Wilson DA, Horn PT: The humanistic burden of hereditary angioedema: Impact on health-related quality of life, productivity, and depression. Allergy Asthma Proc 2010;31:407-414.

6 6 Bygum A, Andersen KE, Mikkelsen CS: Selfadministration of intravenous C1-inhibitor therapy for hereditary angioedema and associated quality of life benefits. Eur J Dermatol 2009;19:147-151.

7 Prior N, Remor E, Gómez-Traseira C, LópezSerrano C, Cabañas R, Contreras J, Campos Á, Cardona V, Cimbollek S, González-Quevedo T, Guilarte M, de Rojas DH, Marcos C, Rubio M, Tejedor-Alonso MÁ, Caballero T: Development of a disease-specific quality of life questionnaire for adult patients with hereditary angioedema due to $\mathrm{C} 1$ inhibitor deficiency (HAE-QoL): Spanish multi-centre research project. Health Qual Life Outcomes 2012;10:82.

-8 Weller K, Groffik A, Magerl M, Tohme N, Martus P, Krause K, Metz M, Staubach P, Maurer M: Development and construct validation of the angioedema quality of life questionnaire. Allergy 2012;67:1289-1298.
9 Caballero T, Sala-Cunill A, Cancian M, Craig TJ, Neri S, Keith PK, Boccon-Gibod I, Bethune C, Bork K: Current status of implementation of self-administration training in various regions of Europe, Canada and the USA in the management of HAE. Int Arch Allergy Immunol 2013;161(suppl 1):10-16.

10 Longhurst HJ, Farkas H, Craig T, AygörenPürsün E, Bethune C, Bjorkander J, Bork K, Bouillet L, Boysen H, Bygum A, Caballero T, Cicardi M, Dempster J, Gompels M, Gooi J, Grigoriadou S, Huffer U, Kreuz W, Levi MM, Long J, Martinez-Saguer I, Raguet M, Reshef A, Bowen T, Zuraw B: HAE international home therapy consensus document. Allergy Asthma Clin Immunol 2010;6:22.

11 Symons C, Rossi O, Magerl M, Andritschke K: Practical approach to self-administration of intravenous C1-INH concentrate: a nursing perspective. Int Arch Allergy Immunol 2013; 161(suppl 1):17-20. 